\title{
Fear, Access, and the Real-Time Estimation of Etiological Parameters for Outbreaks of Novel Pathogens
}

\author{
Authors: Nina H. Fefferman ${ }^{* 1,2}$, Eric T. Lofgren ${ }^{3}$, Nianpeng $\mathrm{Li}^{4}$, Pieter Blue ${ }^{5}$, David J. \\ Weber $^{6}$ and Abdul-Aziz Yakubu ${ }^{4}$. \\ * Corresponding Author: N.H. Fefferman, 447 Hesler Biology Building, Department of Ecology \\ and Evolutionary Biology, University of Tennessee, Knoxville, TN, 37996, email: \\ nfefferm@utk.edu \\ ${ }^{1}$ Department of Ecology and Evolutionary Biology, University of Tennessee, Knoxville, TN, \\ USA \\ ${ }^{2}$ Department of Mathematics, University of Tennessee, Knoxville, TN, USA \\ ${ }^{3}$ Paul G. Allen School for Global Animal Health, Washington State University, Pullman, \\ WA, USA \\ ${ }^{4}$ Department of Mathematics, Howard University, Washington, DC 20059, USA \\ ${ }^{5}$ School of Mathematics, The University of Edinburgh, James Clerk Maxwell Building, The \\ King's Buildings, Mayfield Road, Edinburgh, Scotland \\ ${ }^{6}$ Division of Infectious Diseases, UNC School of Medicine, University of North Carolina at \\ Chapel Hill, Chapel Hill, NC, USA
}

\begin{abstract}
:
Early analysis of outbreaks of novel pathogens to evaluate their likely public health impact depends on fitting predictive models to data gathered and updated in real-time. Both transmission rates and the critical $R_{0}$ threshold (i.e. the pathogen's 'reproductive number') are inferred by finding the values that provide the best model fit to reported case incidence. These models and inferred results are then the basic tools used for public health planning: how many people expected to be infected, at what scales of time and space, and whether potential intervention strategies impact disease transmission and spread. An underlying assumption, however, is that the ability to observe new cases is either constant, or at least constant relative to diagnostic test availability. We present a demonstration, discussion, and mathematical analysis of how this assumption of predictable observability in disease incidence can drastically impact model accuracy. We also demonstrate how to tailor estimations of these parameters to a few examples of different types of shifting influences acting on detection, depending on the likely sensitivity of surveillance systems to errors from sources such as clinical testing rates and differences in healthcare-seeking behavior from the public over time. Finally, we discuss the implications of these corrections for both historical and current outbreaks.

Keywords: Mathematical Epidemiology, Observer Effects, Biosurveillance, Outbreak Modeling, H1N1 2009, COVID-19
\end{abstract}

45

46

47

48 
medRxiv preprint doi: https://doi.org/10.1101/2020.03.19.20038729; this version posted March 20, 2020. The copyright holder for this preprint (which was not certified by peer review) is the author/funder, who has granted medRxiv a license to display the preprint in perpetuity.

It is made available under a CC-BY-NC-ND 4.0 International license .

\section{Introduction:}

51 Mathematical models of the progression of the spread of infectious disease provide the

52 tools used for real-time decision making in public health planning and outbreak

53 management. They allow us to predict the time course of spread within a

54 population(Chowell et al. 2017; Perkins et al. 2016; van den Driessche and Watmough

55 2002), provide critical cost-benefit estimates (Dasbach et al. 2006; Hayman et al. 2017;

56 Keeling et al. 2017; Purdy et al. 2004), and evaluate best practices for particular

57 interventions (Andrews and Basu 2011; Andrews and Bauch 2016; Ferguson et al. 2003;

58 Kretzschmar et al. 2004). When confronted with a novel, potentially virulent pathogen,

59 there is a rush to parameterize models appropriately (Capaldi et al. 2012; Farah et al.

60 2014; Sebrango-RodríGuez et al. 2017; Tizzoni et al. 2012), getting real-time case

61 incidence data from surveillance sources and fitting the models to it to determine the

62 likeliest estimates for probabilities of transmission (i.e. infectiousness) and the basic

63 reproductive number, $R_{0}$, which provides a metric of epidemic potential (Anderson 1991;

64 Chowell et al. 2006; Chowell et al. 2004). As a new outbreak unfolds, updated incidence

65 data helps refine the parameter estimates, shifting our understanding of the nature of the

66 threat in real time (Moore 2004; Sebrango-RodríGuez et al. 2017; Tizzoni et al. 2012).

67 However, many of these models make an explicit assumption that detection of new

68 disease incidence is a function of well-understood confounders that remain mostly

69 invariant over the course of an outbreak, such as the probability of an infected person

70 developing symptoms. There are known corrections for instances that violate this

71 assumption of constant detectability, such as when clinical case definition criteria are 
medRxiv preprint doi: https://doi.org/10.1101/2020.03.19.20038729; this version posted March 20, 2020. The copyright holder for this preprint (which was not certified by peer review) is the author/funder, who has granted medRxiv a license to display the preprint in perpetuity.

It is made available under a CC-BY-NC-ND 4.0 International license .

72 revised (Green 1998; Santermans et al. 2016; Thursky et al. 2003) or when new more

73 sensitive and/or specific diagnostic tests become available (Nouvellet et al. 2015; Villela

74 2017). These confounders, however, are features of the surveillance process itself, and

75 may therefore be understood so long as there is sufficient incorporation of medical and

76 public health practice in the interpretation of the models (Villela 2017). Critically, these

77 surveillance-based step-function changes may not the be the only meaningful factors

78 confounding our ability to accurately estimate incidence data over time, and therefore

79 accurately model the progression of an outbreak.

80

81 The importance of incorporating human behaviors into predictive epidemiological

82 models has gained attention over the past decade (e.g. (Bansal et al. 2007; Del Valle et al.

83 2005; Fenichel et al. 2011; Funk et al. 2010; Perra et al. 2011)). Many models have now

84 explored the potential impact of behaviors that directly impact transmission (e.g. school

85 closures (Earn et al. 2012; Ferguson et al. 2006; Gemmetto et al. 2014; Lofgren et al.

86 2008), social distancing (Glass et al. 2006; Maharaj and Kleczkowski 2012; Reluga 2010;

87 Valdez et al. 2012), use of personal protective equipment (PPE) (Anderson and Garnett

88 2000; Duerr et al. 2007)), etc.). However, the impact of human behavior within the

89 context of epidemic outbreaks is not limited only to those that affect the transmission

90 patterns of the pathogen. Our functioning societies enter into an epidemiological observer

91 effect (cf. (Dirac 1947)) in which various behaviors are likely to confound both the

92 sensitivity and specificity of surveillance detection of disease incidence.

93 
medRxiv preprint doi: https://doi.org/10.1101/2020.03.19.20038729; this version posted March 20, 2020. The copyright holder for this preprint (which was not certified by peer review) is the author/funder, who has granted medRxiv a license to display the preprint in perpetuity.

It is made available under a CC-BY-NC-ND 4.0 International license .

94 Media-fanned public apprehension can create an over-demand for clinical testing

95 (Sharma et al. 2003), even in the absence of clinical signs or symptoms and when

96 transmission from asymptomatic persons does not occur (Baxter 2010). Social

97 stigmatization associated with illness can conversely cause many with symptoms to avoid

98 healthcare providers, and hence diagnosis, for as long as possible in order to avoid social

99 repercussions (e.g. as with HIV/AIDS patients (Chesney and Smith 1999; Kalichman and

100 Simbayi 2003). Even with fully rational and cooperative behavior on the part of the

101 general public, public health directives and media attention will affect physicians

102 themselves, potentially drastically altering rates at which physicians order tests to provide

103 clinical diagnosis rather than relying on palliative treatment without the need for

104 diagnosis (Barras 2020; Cowie et al.). This effect has already been shown to scale

105 disproportionately with the actual rate of incidence (though not the focus of the study,

106 this can be inferred from Fig 2 in (Iowa 1998 Annual Report)).

107

108 Further compounding the potential for these behavioral effects to mislead our models, the

109 behaviors themselves are likely to depend on perceived epidemic status of the population.

110 Individuals may shift their behaviors as reported prevalence rises and falls out of fear, or

111 lack thereof, whether warranted by epidemiological truths or not. Case fatality rates are

112 calculated based both on reported deaths and estimated case incidence, potentially

113 amplifying the feedback since death may be considered an even greater motivator to

114 action than illness. This implies that, not only do we may need to correct our predictive

115 models for the pattern of surveillance sensitivity over time, but also to have sensitivity

116 itself depend on the current perceived prevalence of the disease. This may be even more 
medRxiv preprint doi: https://doi.org/10.1101/2020.03.19.20038729; this version posted March 20, 2020. The copyright holder for this preprint (which was not certified by peer review) is the author/funder, who has granted medRxiv a license to display the preprint in perpetuity.

It is made available under a CC-BY-NC-ND 4.0 International license .

117 critical in instances where estimated case incidence does not accurately reflect numbers

118 of infections (i.e. when case fatality rates and infection fatality rates differ significantly).

119 In effect, modeling efforts should be split into separate endeavors: one of curve fitting for

120 observed incidence, and one of inferring from those curves the likely underlying, actual

121 disease process.

122

123 To capture this coupled process of disease dynamics and disease detection, we consider a

124 standard, simple epidemiological model, but incorporate the potential for errors derived

125 from a variety of sources that confound our estimates of case incidence. We use these

126 models to demonstrate how these corrections would alter our understanding of historical

127 outbreaks, and then discuss some evidence that modern outbreaks are affected by the

128 types of behavioral shifts that we consider.

130

\section{Methods/ Model}

132 We begin with a standard Susceptible-Infected-Recovered (SIR) system, however, we

133 will examine both "real" process of actual pathogen spread (denoted by the subscript $a$ ),

134 and a "perceived" or "measured" process (denoted by the subscript $m$ ). For simplicity

135 sake, we will assume that correct diagnosis and treatment has no bearing on the duration

136 of illness/ recovery time, nor on the rates of transmission from infected to susceptible

137 individuals. Although both of these are obviously false for most outbreaks, they allow us

138 to highlight the processes and methods most relevant to our purpose here and are easily

139 corrected in specific application to particular outbreaks in the future. We therefore 
medRxiv preprint doi: https://doi.org/10.1101/2020.03.19.20038729; this version posted March 20, 2020. The copyright holder for this preprint (which was not certified by peer review) is the author/funder, who has granted medRxiv a license to display the preprint in perpetuity.

It is made available under a CC-BY-NC-ND 4.0 International license .

140 assume that the recovery rate, $\gamma$, is the same in both the perceived and real processes (i.e.

$\left.141 \gamma_{a}=\gamma_{m}=\gamma\right)$.

142 This therefore yields a "real" process of $\frac{d s_{a}}{d t}=-\beta_{a} s_{a} i_{a}, \frac{d i_{a}}{d t}=\beta_{a} s_{a} i_{a}-\dot{i}_{a}$, and

$143 r_{a}(t)=1-s_{a}(t)-i_{a}(t)$, where $s_{a}(t), i_{a}(t)$, and $r_{a}(t)$ are the fractions of the populations

144 in the respective health categories at time $t$. To build the perceived disease process from

145 this model, we then incorporate rates of testing for each fraction of the population, and

146 the sensitivity and specificity of the test as follows.

148 Importantly, we will define as susceptible any person one who is not infected with our the 149 pathogen of concern, despite possible infection with another illness. It is therefore not

150 only reasonable but probable that "susceptible people" will seek out health care services

151 and be tested for infection under our surveillance process, especially if the symptoms of

152 their infection closely match those of the pathogen causing our focal outbreak. We

153 therefore define $\alpha$ to be the rate at which susceptible people are tested for illness, call $\delta$

154 the rate at which infected people are tested for illness, and call $\lambda$ the rate at which

155 recovered people are tested for illness. (For purposes of this paper, we will assume

$156 \alpha=\lambda$, however this assumption may be relaxed in future work if memory of recently

157 resolved symptoms affects health care seeking behavior). We define the false positive

158 rate of the diagnostic test $\varepsilon_{1}$ and the false negative rate of the test $\varepsilon_{2}$ (these may apply

159 either to clinical diagnostic sensitivity and specificity, or else to error rates stemming

160 from differences in physician opinion during syndromic surveillance). 
medRxiv preprint doi: https://doi.org/10.1101/2020.03.19.20038729; this version posted March 20, 2020. The copyright holder for this preprint

162 Assuming that, at least initially, our surveillance cannot determine whether an uninfected

163 person is susceptible or recovered, and therefore $s_{m}(t)+i_{m}(t)=1$, we can define

$164 s_{m}=s_{a}(1-\alpha)+s_{a} \alpha\left(1-\varepsilon_{1}\right)+i_{a}(1-\delta)+i_{a} \delta \varepsilon_{2}+r_{a}(1-\lambda)+r_{a} \lambda\left(1-\varepsilon_{1}\right)$ and

$165 i_{m}=s_{a}\left(\alpha \varepsilon_{1}-\lambda \varepsilon_{1}\right)+i_{a}\left(\delta-\delta \varepsilon_{2}-\lambda \varepsilon_{1}\right)+\lambda \varepsilon_{1}$. Defined in this way, if $\alpha=\delta=\lambda=1$, and

$166 \varepsilon_{1}=\varepsilon_{2}=0$, and $r_{a}=0$, then $i_{m}=i_{a}$ and $s_{m}=s_{a}$ (i.e. when there are no errors and the

167 surveillance is perfect, then the measured case incidence will be equal to the

168 corresponding real case incidence, as we would hope).

170 Using this definition, we then correct our understanding of any disease incidence curve

171 once we have either measured or assumed appropriate functions/values for $\alpha, \delta, \lambda, \varepsilon_{1}$,

172 and $\varepsilon_{2}$. While this might at first seem straightforward, there arises the complication that

173 our health care seeking behavior functions are likely to be problematic in at least three

174 separate ways: (1) they are likely to be functions of the current perceived prevalence of

175 infection in the population (i.e. some function of $i_{m}$ ), (2) they are likely to be functions of

176 time since the beginning of the perception of the current outbreak, (3) they are likely to

177 be non-linear and, in some cases, not even continuous. We therefore propose the

178 following algorithm to produce a system of SIR curves which reflect the underlying

179 disease dynamics without the influence of behavioral shifts and/or testing inaccuracy; we

180 will denote this system as "Testing Neutral", TN.

181

182 We start from the most conservative assumption: that only the epidemiological rates of

$183 \beta_{m}$ and $\gamma$ for the outbreak curve of interest are known (i.e. that the raw data to which an 
medRxiv preprint doi: https://doi.org/10.1101/2020.03.19.20038729; this version posted March 20, 2020. The copyright holder for this preprint

184 SIR model was fit to obtain those parameters is currently unavailable). We make this

185 assumption to provide a method by which analysis of previously published rates for

186 historical outbreaks could be analyzed without having to reanalyze the original outbreak

187 data (should that data in fact be accessible, the correction can naturally be applied

188 directly to the $i_{m}$ data directly rather than to $i^{*}$ curve described below). We, therefore,

189 begin with an initially reconstructed SIR system (denoted by *) using only our measured

$190 \quad \beta_{m}$ and $\gamma: \frac{d s^{*}}{d t}=-\beta_{m} s^{*} i^{*}$ and $\frac{d i^{*}}{d t}=\beta_{m} s^{*} i^{*}-\dot{x}^{*}$. We then compute the corrected curve

191 for the infected population (which is no longer necessarily continuous) using the

192 definition of $i_{m}$ above and applying it to the $i^{*}$ and $i_{c o r}$ instead of $i_{m}$ and $i_{a}$

193 (respectively), we obtain $i_{c o r}=\frac{i^{*}-\varepsilon_{1} \alpha}{\delta\left(1-\varepsilon_{2}\right)-\varepsilon_{1} \alpha}$ so long as $\frac{\varepsilon_{1} \alpha}{\left(1-\varepsilon_{2}\right)} \neq 1$ (note: if it is equal

194 to 1 , then $i^{*}=\alpha$, which implies that the surveillance process cannot accurately capture

195 the underlying real disease dynamics; derivation of this equality can be found in ESM

196 Appendix 1). We are then able to generate the TN system by finding a new value of $\beta$

197 which minimizes the square of the distance between the $i_{c o r}(t)$ curve and a new,

198 hypothetical, standard continuous SIR system's infected curve, using the known value of

$199 \gamma$. We call this new, corrected value the "Testing Neutral $\beta$ " which we denote $\beta_{T N}$. So

200 long as our assumed rates and behavior adjustment functions are reasonable

201 approximations of the associated real-world values and behaviors, $\beta_{T N}=\beta_{a}$, and the TN

202 system may reasonably approximate the real disease dynamics (i.e. $s_{T N}=s_{a}, i_{T N}=i_{a}$,

203 using the rates $\beta_{T N}$ and $\gamma$ ). These values of $\beta_{a}$ and $\gamma$ (and by extension, the $R_{0}$

204 computed either by fitting $i_{T N}=i_{a}$, or else computed as the ratio of these corrected 
medRxiv preprint doi: https://doi.org/10.1101/2020.03.19.20038729; this version posted March 20, 2020. The copyright holder for this preprint (which was not certified by peer review) is the author/funder, who has granted medRxiv a license to display the preprint in perpetuity.

It is made available under a CC-BY-NC-ND 4.0 International license .

205 etiological rates) may then be compared to similarly corrected values for other outbreaks

206 without worry that differences in sensitivity or health-care seeking behavior will

207 influence the comparison.

208

209 Results

210

211 Demonstration of Impact of Healthcare-Seeking Behavior, Clinical Testing Rates, and

212 Diagnostic Error Rates on Estimation of Outbreak Dynamics and Severity

213

214 To demonstrate the potential of these types of confounding factors in incidence

215 estimation to influence our understanding of ongoing disease dynamics, we present the

$216 i_{m}$ and $i_{a}$ curves under a variety of values for $\varepsilon_{1}$, and $\varepsilon_{2}$, and function choices for $\alpha$

217 and $\delta$. Even under the simplest exploratory case, in which there are no ongoing

218 dynamics affecting the ability to estimate incidence over time and where also the rates of

219 testing for susceptible, infected, and recovered individuals are all held constant and

220 identical, we see that asymmetry in error type rates alone can drastically alter our

221 understanding of an ongoing outbreak (Fig. 1a). Extending this simple case to also

222 include behavioral responses that shift over the course of an outbreak (i.e. non-constant

223 testing rates), while still keeping all else the same, we see also that there can be drastic

224 errors, even in the understood shape of the incidence curve to match the cases observed

225 (Fig. 1b). (Again, for derivation of predictions for agreement/disagreement with real

226 disease process based on the direction of the inequality between $A_{\varepsilon}$ and 1 , and the

227 derivation of this example, see ESM Appendix 1). 
medRxiv preprint doi: https://doi.org/10.1101/2020.03.19.20038729; this version posted March 20, 2020. The copyright holder for this preprint (which was not certified by peer review) is the author/funder, who has granted medRxiv a license to display the preprint in perpetuity.

It is made available under a CC-BY-NC-ND 4.0 International license .

228 Note that these calculations presented in Figure 1 are meant to be extremes to highlight

229 the potential for confusion - we show a full range of values for $\varepsilon_{1}$, and $\varepsilon_{2}$ ranging from

230 potentially realistic $\left(A_{\varepsilon}=1\right)$ to dramatically inflated (both $\varepsilon_{1}$, and $\varepsilon_{2}$ are greater than 0.5 ,

231 which would result in a more accurate test by simply negating the result). This is done to

232 highlight the problem, though of course, real-world values are expected to be within a

233 much narrower, more conservative range.

235 Data-Driven Case Studies

237 Historical Outbreaks of Pandemic Influenza

238 Employing this now demonstrated potential for mismatch in understood dynamics to

239 more realistic outbreak scenarios, we see that when health-care seeking behavior is

240 dependent on the perceived prevalence of disease, shifting at a set threshold, there is also

241 the potential for drastic misunderstanding of the disease dynamics, even if the error rates

242 in testing are realistically low (Ai et al. 2020; Chu et al. 2012) (Fig 2a). Further departing

243 from an idealized instructional case, when we incorporate both testing rate dependence

244 on perceived prevalence and the amount of time since surpassing the threshold for

245 increased behavioral demand for testing (e.g. gradual relaxation in public risk perception

246 over time), the differences between the reality of the disease dynamics and the

247 understanding that would be provided by fitting a model to case incidence data is even

248 greater (Fig 2b). 
medRxiv preprint doi: https://doi.org/10.1101/2020.03.19.20038729; this version posted March 20, 2020. The copyright holder for this preprint (which was not certified by peer review) is the author/funder, who has granted medRxiv a license to display the preprint in perpetuity.

It is made available under a CC-BY-NC-ND 4.0 International license .

250 To demonstrate how these effects might impact current understanding of modern

251 analyses, we construct a hypothetical scenario using results from an excellent paper

252 comparing the severity of pandemic and epidemic outbreaks of influenza: Viboud et al.

2532006 (Viboud et al. 2006). In this paper, the authors concluded (among other things) that

254 the $R_{0}$ values for three pandemic years $(1918,1957$, and 1968) were $2.1,1.5$ and 1.8

255 (respectively). However, while all three pandemic years of data were analyzed using

256 transmission estimates inferred from influenza-attributed mortality data, the data for the

2571957 and 1968 years were based upon WHO laboratory surveillance. For this reason, we

258 can assume that the reported influenza attributed mortality was more accurate in

259 representing only deaths from influenza (or associated pneumonia) than would have been

260 possible for 1918. Entirely hypothetically, even if we assume that health care seeking

261 behavior did not change at all between 1918 and 1957 (purely for demonstration, we

262 assume $\alpha=\left\{\begin{array}{c}0.01 \text { if } i_{m} \leq 0.05 \\ 0.8 \text { if } i_{m}>0.05\end{array}\right.$ and $\delta=\left\{\begin{array}{l}0.5 \text { if } i_{m} \leq 0.01 \\ 1.0 \text { if } i_{m}>0.01\end{array}\right.$ for all of these analyses), if we posit

263 that the syndromic surveillance of 1918 led to error rates of $\varepsilon_{1}=0.1$ and $\varepsilon_{2}=0.005$,

264 whereas the laboratory based testing was able to increase the specificity of the diagnosis

265 (leaving the sensitivity the same) to $\varepsilon_{1}=0.01$, we already see a drop in the perceived vs

266 TN estimates of $R_{0}$ for 1918 from 2.1 to 1.9 , but no change (after rounding to the same

267 number of digits) in the $R_{0}$ estimates for either 1957 or 1968 . This leads to a substantial

268 mismatch in the observed incidence curve for the 1918 pandemic and an understanding of

269 the same outbreak under a Testing Neutral assumption (Fig 3a) while both the 1957 and

2701958 outbreaks would already have been accurately understood (Fig 3b and 3c).

271 
medRxiv preprint doi: https://doi.org/10.1101/2020.03.19.20038729; this version posted March 20, 2020. The copyright holder for this preprint (which was not certified by peer review) is the author/funder, who has granted medRxiv a license to display the preprint in perpetuity.

It is made available under a CC-BY-NC-ND 4.0 International license .

272 While we have no reason to suspect that our hypothetical error rates and assumed health

273 care seeking behavioral functions reflect the reality of any of these three pandemics, they

274 are clearly within realistic ranges and therefore demonstrate how dramatic the impact of

275 even small differences in diagnostic sensitivity (whether due to changes in laboratory

276 practice or to patient- or physician-driven behavior) can be on epidemiological estimates

277 on which we base our public health strategies and policies.

278

279 Outbreak of Influenza H1N1-09

280

281 Whereas case studies of historical outbreaks of pandemic influenza allowed us to

282 demonstrate the potential misestimate for $R_{0}$ and resulting disease dynamics in the

283 absence of direct understanding of behavioral shifts in testing practices, the more recent

284 "novel" (H1N1-09) provides instead real-world data on the shifting demand for clinical

285 diagnostic testing. This pandemic was first brought to light by global media attention in

286 advance of clinical diagnosis in many areas. This is made clear by considering a time-

287 series of both ordered clinical tests and confirmed cases of H1N1 in the UNC healthcare

288 system in 2009 in which testing started immediately after media attention to the virus, but

289 significantly before any actual circulation was detected (Fig. 4a).

291 Using the actual sensitivity and specificity known for the H1N1 tests in use at the time

292 (Ginocchio et al. 2009), and the UNC testing curve to parameterize demand, we see that

293 the reported estimate of $R_{0}=1.58$ (Fraser et al. 2009), under correction, instead becomes

294 and $R_{0}=1.64$ (Fig. 4b). Of potential note, if we restrict the window for curve fitting to 
medRxiv preprint doi: https://doi.org/10.1101/2020.03.19.20038729; this version posted March 20, 2020. The copyright holder for this preprint (which was not certified by peer review) is the author/funder, who has granted medRxiv a license to display the preprint in perpetuity.

It is made available under a CC-BY-NC-ND 4.0 International license .

295 just the first weeks' worth of data, we instead get an estimated $R_{0}=1.66$ (Fig. 4c),

296 meaning that, for this scenario, earlier estimates and projections were likely to

297 overestimate the progression of the outbreak slightly. Depending on whether or not the

298 UNC data is actually representative of broader patterns of test-seeking or test-ordering

299 behavior this provides evidence that our understanding of the global dynamics of novel

$300 \quad$ H1N1 in 2009 may be flawed.

301

302 Outbreak of COVID-19

303 While we have no way of currently estimating the rate of susceptible individuals seeking

304 testing, we can make some generalizations given that the demand for testing in the United

305 States as of 17 March well outstripped the supply of tests, and access to these tests was

306 decidedly non-uniform (e.g. supplemental test availability from the Seattle Flu Study).

308 Analytic Condition for Accuracy in Estimated Case Incidence from Surveillance

309

310 In addition to these numerical examples, we provide a theoretical threshold condition,

$311 \bar{A}_{\varepsilon}$, for the ability of a surveillance system to reflect actual disease incidence based on

312 assumed relationships among the behavioral functions and error rates (much as $R_{0}$

313 provides a threshold condition for epidemics). Assuming that the behavioral health care

314 seeking functions are independent of time, the effective ratio of error rates in the

315 diagnostic tests, defined as $A_{\varepsilon}=\frac{\varepsilon_{1}}{\left(1-\varepsilon_{2}\right) j\left(i_{m}\right)}$, where $j\left(i_{m}\right)=\delta / \alpha$, can be used to define 
medRxiv preprint doi: https://doi.org/10.1101/2020.03.19.20038729; this version posted March 20, 2020. The copyright holder for this preprint (which was not certified by peer review) is the author/funder, who has granted medRxiv a license to display the preprint in perpetuity.

$316 \bar{A}_{\varepsilon}=\left\{\begin{array}{l}A_{\varepsilon}, \text { if } \phi\left(i_{m}\right)-i_{m} \phi^{\prime}\left(i_{m}\right)>0 ; \\ \frac{1}{A_{\varepsilon}}, \text { if } \phi\left(i_{m}\right)-i_{m} \phi^{\prime}\left(i_{m}\right)<0\end{array}\right.$ where $\phi\left(i_{m}\right)=\alpha$. This $\bar{A}_{\varepsilon}$ then provides a way to

317 determine whether the perceived or measured disease process may accurately reflect the

318 real, underlying disease process. In this case, when the ratio of the diagnosis test rates is

319 constant, if there are no errors in the diagnosis tests then the surveillance accurately

320 reflects the real disease process though it may overestimate or underestimate actual

321 incidence. If there are errors, the surveillance system accurately reflects the increasing or

322 decreasing nature of the real disease if $\bar{A}_{\varepsilon}<1$, but can indicate increasing (resp.

323 decreasing) incidence while the actual incidence is decreasing (resp. increasing) when

$324 \bar{A}_{\varepsilon}>1$. When the ratio of the diagnosis tests is non-constant the results are more

325 complicated, but some results are still accessible: without errors in diagnostic tests, a

326 surveillance system can wrongly report no disease incidence while actual case incidence

327 is either increasing or decreasing. Further, with small errors in the diagnostic tests it is

328 possible for a surveillance system to report decreasing incidence while the actual

329 incidence is increasing. (Proofs and characterizations of these relationships are provided

330 in ESM Appendix 1.)

331

332 Discussion

333

334 The ability to accurately infer epidemiological rates from outbreak data is critical to a

335 majority of our public health planning efforts. As our models demonstrate, the accuracy

336 of our estimates may be significantly compromised by our implicit assumption that

337 diagnostic error rates and health care seeking behavior remain constant over the course of 
medRxiv preprint doi: https://doi.org/10.1101/2020.03.19.20038729; this version posted March 20, 2020. The copyright holder for this preprint (which was not certified by peer review) is the author/funder, who has granted medRxiv a license to display the preprint in perpetuity.

It is made available under a CC-BY-NC-ND 4.0 International license .

338 single, and even multiple, outbreaks, even as we know this assumption to be untrue.

339 Regardless of the particular mechanism through which we attempt to characterize the

340 changes in diagnostic sensitivity and specificity, our results demonstrate (in both theory

341 and practice) how these dynamics may be incorporated into epidemiological modeling

342 efforts and how the results may translate into a more accurate understanding of infectious

343 disease dynamics.

345 Some studies have been able to assess the impact of public health announcement- or

346 media-driven behavioral change with regard to disease risk and diagnosis (e.g. (Sharma et

347 al. 2003)). It is clear that we will need to develop better models that explicitly capture the

348 major factors that can effect change in public behavior regarding health care and

349 diagnosis. While it may be impossible to accurately assess the impact of behavioral

350 changes in health care seeking behavior for past epidemics, one possible course of action

351 going forwards would be to ask physicians, hospitals and laboratories to record and report

352 the number of tests performed in addition to merely the number of cases positively

353 diagnosed, regardless of acknowledge threat of outbreaks.

355 These models and insights may also be of critical use our collective ongoing efforts to

356 understand and predict the progression of COVID-19. Not only do we provide the

357 obvious alternations to the standard epidemic predictions for error rates in testing, we

358 also provide a mechanism by which to correct our understanding of $R_{0}$ based on changes

359 in access to tests of various sensitivities and specificities over time. This is especially

360 important given both the formulation of governmental responses to the pandemic (i.e. 
medRxiv preprint doi: https://doi.org/10.1101/2020.03.19.20038729; this version posted March 20, 2020. The copyright holder for this preprint (which was not certified by peer review) is the author/funder, who has granted medRxiv a license to display the preprint in perpetuity.

It is made available under a CC-BY-NC-ND 4.0 International license .

361 "flattening the curve" or relying on community protection, i.e. 'herd immunity') and their

362 subsequent evaluation hinge on accurate estimations of $R_{0}$. While presented here with

363 constant rates to enable the analytic calculations, real-time estimations of $R_{0}$ are

364 frequently based on numerical solutions, rather than analytic calculations. In this case, the

365 expansion of precisely these equations to allow for $\alpha, \delta$, and $\lambda$ to themselves be

366 dynamic functions of public perception and disease prevalence will enable vastly more

367 accurate understanding of real-time case incidence data. Work currently underway to try

368 and capture the functional forms of these responses in observed behaviors in the US will

369 hopefully allow us to extend these results very soon to the ongoing COVID-19 pandemic

370 itself, but we provide this model in the meanwhile to allow others to work in parallel and

371 improve our real-time decision-support capabilities.

372 
medRxiv preprint doi: https://doi.org/10.1101/2020.03.19.20038729; this version posted March 20, 2020. The copyright holder for this preprint (which was not certified by peer review) is the author/funder, who has granted medRxiv a license to display the preprint in perpetuity.

It is made available under a CC-BY-NC-ND 4.0 International license .

\section{Literature Cited}

Ai, T., Z. Yang, H. Hou, C. Zhan, C. Chen, W. Lv, Q. Tao et al. 2020. Correlation of chest CT and RT-PCR testing in coronavirus disease 2019 (COVID-19) in China: a report of 1014 cases. Radiology:200642.

Anderson, R., May, R.M. 1991, Infectious disease of humans. Oxford, UK, Oxford University Press.

Anderson, R. M., and G. P. Garnett. 2000. Mathematical models of the transmission and control of sexually transmitted diseases. Sexually Transmitted Diseases 27:636643.

Andrews, J. R., and S. Basu. 2011. Transmission dynamics and control of cholera in Haiti: an epidemic model. The Lancet 377:1248-1255.

Andrews, M. A., and C. T. Bauch. 2016. The impacts of simultaneous disease intervention decisions on epidemic outcomes. Journal of theoretical biology 395:1-10.

Bansal, S., B. T. Grenfell, and L. A. Meyers. 2007. When individual behaviour matters: homogeneous and network models in epidemiology. Journal of the Royal Society Interface 4:879-891.

Barras, C. 2020. Major testing issues in US, Pages 8, New Scientist, Elsevier.

Baxter, R. 2010. Surveillance lessons from first-wave pandemic (H1N1) 2009, Northern California, USA. Emerging infectious diseases 16:504.

Capaldi, A., S. Behrend, B. Berman, J. Smith, J. Wright, and A. L. Lloyd. 2012. Parameter estimation and uncertainty quantication for an epidemic model. Mathematical biosciences and engineering:553.

Chesney, M. A., and A. W. Smith. 1999. Critical delays in HIV testing and care - The potential role of stigma. American Behavioral Scientist 42:1162-1174.

Chowell, G., C. E. Ammon, N. W. Hengartner, and J. M. Hyman. 2006. Estimation of the reproductive number of the Spanish flu epidemic in Geneva, Switzerland. Vaccine 24:6747-6750.

Chowell, G., N. W. Hengartner, C. Castillo-Chavez, P. W. Fenimore, and J. M. Hyman. 2004. The basic reproductive number of Ebola and the effects of public health measures: the cases of Congo and Uganda. Journal of theoretical biology 229:119-126.

Chowell, G., C. Viboud, L. Simonsen, S. Merler, and A. Vespignani. 2017. Perspectives on model forecasts of the 2014-2015 Ebola epidemic in West Africa: lessons and the way forward. BMC medicine 15:42.

Chu, H., E. T. Lofgren, M. E. Halloran, P. F. Kuan, M. Hudgens, and S. R. Cole. 2012. Performance of rapid influenza H1N1 diagnostic tests: a meta $\square$ analysis. Influenza and other respiratory viruses 6:80-86.

Cowie, G. A., B. C. Cowie, and J. E. Fielding. Influenza testing trends in sentinel surveillance general practices in Victoria 2007 to 2014 The Victorian Sentinel Practice Influenza Network (VicSPIN) conducts surveillance for syndromic and laboratory confirmed influenza in approximately 100 general practices in Victoria each influenza season. Participating general practitioners test for influenza at their own discretion-the percentage of patients swabbed within and between seasons is evaluated. Page last updated: 30 March 2017. 
Dasbach, E. J., E. H. Elbasha, and R. P. Insinga. 2006. Mathematical models for predicting the epidemiologic and economic impact of vaccination against human papillomavirus infection and disease. Epidemiologic Reviews 28:88-100. behavioral changes in a smallpox attack model. Mathematical Biosciences 195:228-251.

Dirac, P. A. M. 1947, The principles of quantum mechanics. Oxford, Clarendon Press.

Duerr, H. P., S. O. Brockmann, I. Piechotowski, M. Schwehm, and M. Eichner. 2007. Influenza pandemic intervention planning using InfluSim: pharmaceutical and non-pharmaceutical interventions. Bmc Infectious Diseases 7:13.

Earn, D. J. D., D. He, M. B. Loeb, K. Fonseca, B. E. Lee, and J. Dushoff. 2012. Effects of school closure on incidence of pandemic influenza in Alberta, Canada. Annals of internal medicine 156:173-181.

Farah, M., P. Birrell, S. Conti, and D. D. Angelis. 2014. Bayesian emulation and calibration of a dynamic epidemic model for A/H1N1 influenza. Journal of the American Statistical Association 109:1398-1411.

Fenichel, E. P., C. Castillo-Chavez, M. G. Ceddia, G. Chowell, P. A. G. Parra, G. J. Hickling, G. Holloway et al. 2011. Adaptive human behavior in epidemiological models. Proceedings of the National Academy of Sciences 108:6306-6311.

Ferguson, N. M., D. A. T. Cummings, C. Fraser, J. C. Cajka, P. C. Cooley, and D. S. Burke. 2006. Strategies for mitigating an influenza pandemic. Nature 442:448452.

Ferguson, N. M., M. J. Keeling, W. J. Edmunds, R. Gant, B. T. Grenfell, R. M. Amderson, and S. Leach. 2003. Planning for smallpox outbreaks. Nature 425:681685.

Fraser, C., C. A. Donnelly, S. Cauchemez, W. P. Hanage, M. D. Van Kerkhove, T. D. Hollingsworth, J. Griffin et al. 2009. Pandemic potential of a strain of influenza A (H1N1): early findings. Science 324:1557-1561.

Funk, S., M. Salathé, and V. A. Jansen. 2010. Modelling the influence of human behaviour on the spread of infectious diseases: a review. Journal of The Royal Society Interface 7:1247-1256.

Gemmetto, V., A. Barrat, and C. Cattuto. 2014. Mitigation of infectious disease at school: targeted class closure vs school closure. BMC infectious diseases 14:695.

Ginocchio, C. C., F. Zhang, R. Manji, S. Arora, M. Bornfreund, L. Falk, M. Lotlikar et al. 2009. Evaluation of multiple test methods for the detection of the novel 2009 influenza A (H1N1) during the New York City outbreak. Journal of Clinical Virology 45:191-195.

Glass, R. J., L. M. Glass, W. E. Beyeler, and H. J. Min. 2006. Targeted Social Distancing Design for Pandemic Influenza. Emerging Infectious Diseases 12:11.

Green, T. A. 1998. Using surveillance data to monitor trends in the AIDS epidemic. Statistics in medicine 17:143-154.

Hayman, D., J. Marshall, N. French, T. Carpenter, M. Roberts, and T. Kiedrzynski. 2017. Cost-benefit analyses of supplementary measles immunisation in the highly immunized population of New Zealand. Vaccine 35:4913-4922.

Iowa, S. H. L. a. U. o. 1998 Annual Report. Eastern Iowa Whooping Cough Outbreak. 
Kalichman, S. C., and L. C. Simbayi. 2003. HIV testing attitudes, AIDS stigma, and voluntary HIV counselling and testing in a black township in Cape Town, South Africa. Sexually Transmitted Infections 79:442-447.

Keeling, M. J., K. A. Broadfoot, and S. Datta. 2017. The impact of current infection levels on the cost-benefit of vaccination. Epidemics 21:56-62.

Kretzschmar, M., S. van den Hof, J. Wallinga, and J. van Wijngaarden. 2004. Ring vaccination and smallpox control. Emerging Infectious Diseases 10:832-841.

Lofgren, E. T., J. Rogers, M. Senese, and N. H. Fefferman. 2008. Pandemic preparedness strategies for school systems: is closure really the only way? Annales Zoologici Fennici 45:449-458.

Maharaj, S., and A. Kleczkowski. 2012. Controlling epidemic spread by social distancing: Do it well or not at all. BMC Public Health 12:679.

Moore, K. 2004. Real-time syndrome surveillance in Ontario, Canada: the potential use of emergency departments and Telehealth. European Journal of Emergency Medicine 11:3-11.

Nouvellet, P., T. Garske, H. L. Mills, G. Nedjati-Gilani, W. Hinsley, I. M. Blake, M. D. Van Kerkhove et al. 2015. The role of rapid diagnostics in managing Ebola epidemics. Nature 528:S109.

Perkins, T. A., A. S. Siraj, C. W. Ruktanonchai, M. U. G. Kraemer, and A. J. Tatem. 2016. Model-based projections of Zika virus infections in childbearing women in the Americas. Nature microbiology 1:16126.

Perra, N., D. Balcan, B. Gonçalves, and A. Vespignani. 2011. Towards a characterization of behavior-disease models. PloS one 6.

Purdy, K. W., J. W. Hay, M. F. Botteman, and J. I. Ward. 2004. Evaluation of strategies for use of acellular pertussis vaccine in adolescents and adults: A cost-benefit analysis. Clinical Infectious Diseases 39:20-28.

Reluga, T. C. 2010. Game theory of social distancing in response to an epidemic.

Santermans, E., E. Robesyn, T. Ganyani, B. Sudre, C. Faes, C. Quinten, W. Van Bortel et al. 2016. Spatiotemporal evolution of Ebola virus disease at sub-national level during the 2014 West Africa epidemic: model scrutiny and data meagreness. PloS one 11.

Sebrango-RodríGuez, C. R., D. A. MartíNez-Bello, L. SÁNchez-ValdÉS, P. J. Thilakarathne, E. Del Fava, P. Van Der Stuyft, A. LÓPez-QuÍLez et al. 2017. Real-time parameter estimation of Zika outbreaks using model averaging. Epidemiology \& Infection 145:2313-2323.

Sharma, V., M. D. Dowd, D. S. Swanson, A. J. Slaughter, and S. D. Simon. 2003. Influence of the news media on diagnostic testing in the emergency department. Archives of Pediatrics \& Adolescent Medicine 157:257-260.

Thursky, K., S. P. Cordova, D. Smith, and H. Kelly. 2003. Working towards a simple case definition for influenza surveillance. Journal of Clinical Virology 27:170179.

Tizzoni, M., P. Bajardi, C. Poletto, J. J. Ramasco, D. Balcan, B. Gonçalves, N. Perra et al. 2012. Real-time numerical forecast of global epidemic spreading: case study of 2009 A/H1N1pdm. BMC medicine 10:165.

Valdez, L. D., P. A. Macri, and L. A. Braunstein. 2012. Intermittent social distancing strategy for epidemic control. Physical Review E 85:036108. 
medRxiv preprint doi: https://doi.org/10.1101/2020.03.19.20038729; this version posted March 20, 2020. The copyright holder for this preprint

(which was not certified by peer review) is the author/funder, who has granted medRxiv a license to display the preprint in perpetuity.

It is made available under a CC-BY-NC-ND 4.0 International license .

509 van den Driessche, P., and J. Watmough. 2002. Reproduction numbers and sub-threshold $510 \quad$ endemic equilibria for compartmental models of disease transmission.

$511 \quad$ Mathematical Biosciences 180:29-48.

512 Viboud, C., T. Tam, D. Fleming, A. Handel, M. A. Miller, and L. Simonsen. 2006.

513 Transmissibility and mortality impact of epidemic and pandemic influenza, with

514 emphasis on the unusually deadly 1951 epidemic. Vaccine 24:6701-6707.

515 Villela, D. A. M. 2017. Imperfect testing of individuals for infectious diseases:

$516 \quad$ Mathematical model and analysis. Communications in Nonlinear Science and

517

518

519

520 
Figure Legends

Figure 1: Example Perceived and Infected Curves Representing the Same Outbreak Under Different Testing Rates/Functions. All curves: $\beta_{a}=3, \gamma=1$, $s_{a}(0)=0.9, i_{a}(0)=0.1$. (a) Constant Behavioral Responses. Black solid curve: real disease dynamics; Black $\boldsymbol{\square}: \alpha=0.65, \delta=0.65, \varepsilon_{1}=0.2$, and $\varepsilon_{2}=0.1$; Dashed curve: $\alpha=0.65, \delta=0.65, \varepsilon_{1}=0.6$, and $\varepsilon_{2}=0.7$; Black $\mathbf{X}$ : when the effective ratio of errors in testing, $A_{\varepsilon}=1$ (for calculations, see Appendix 1). (b) Non-Constant Behavioral Responses: All curves: $\beta_{a}=3, \gamma=1, s_{a}(0)=0.9$, $i_{a}(0)=0.1$. Black curve: real disease dynamics; All other curves $\alpha=0.65$, $\delta=\frac{0.65\left(1+q i_{m}\right)}{p i_{m}}, p=q=1,\left(\varepsilon_{1}\right.$ and $\varepsilon_{2}$ for each curve as labeled $)$.

Figure 2: Example Perceived and TN Infected Curves Representing the Same Outbreak. (a) Non-Constant Health Care Seeking Behavior Functions. All curves: $\gamma=1, s_{a}(0)=0.999, i_{a}(0)=0.001$. Solid curve - Perceived Outbreak: $\beta_{m}=1.15, \alpha=\left\{\begin{array}{c}0.01 \text { if } i_{m} \leq 0.003 \\ 0.8 \text { if } i_{m}>0.003\end{array}, \delta=\left\{\begin{array}{l}0.5 \text { if } i_{m} \leq 0.001 \\ 1.0 \text { if } i_{m}>0.001\end{array}, \varepsilon_{1}=0.002\right.\right.$, and $\varepsilon_{2}=0.005 ;$ Dotted curve - Testing Neutral Outbreak: $\beta_{T N}=1.13$

(b) Healthcare Seeking Behavior Functions that Depend on Perceived Epidemic Severity and Time from first Outbreak Identification. All curves: $\gamma=1$, $s_{a}(0)=0.999, i_{a}(0)=0.001$. Solid curve - Perceived Outbreak: $\beta_{m}=1.15$, $\alpha=\left\{0.01\right.$ if $i_{m}$ has never exceeded 0.003 , and 0.7 when $i_{m}$ first exceeds 0.003 , decreasing exponentially (by a factor of $e^{(x-t)}$ ) over time to 0.3$\}$, $\delta=\left\{\begin{array}{l}0.5 \text { if } i_{m} \leq 0.001 \\ 1.0 \text { if } i_{m}>0.001\end{array}, \varepsilon_{1}=0.01\right.$, and $\varepsilon_{2}=0.005 ;$ Dotted curve - Testing Neutral Outbreak: $\beta_{T N}=1.10$

Figure 3: Differences in Estimates of $R_{0}$ for Three Pandemic Years Using Hypothetical Correction Rates. (a) Analysis of Influenza Pandemic of 1918, (b) Analysis of Influenza Pandemic of 1957, (c) Analysis of Influenza Pandemic of 1968. For all panels - Solid line: Perceived/Reported pandemic incidence curve, reconstructed from reported $R_{0}$. Dotted line: TN pandemic incidence curves $\left(1918 \mathrm{TN} R_{0}=1.9 ; \mathrm{TN} 1957 R_{0}=1.5 ; 1968 \mathrm{TN} R_{0}=1.8\right)$.

Figure 4: Testing Rates and Resulting Estimates of $R_{0}$ for Novel H1N1 2009. (a) Counts of influenza tests ordered and H1N1 positive tests from UNC, (b) Estimated epidemic curves from reported (solid line) and TN (dotted line) epidemic incidence curves using the full time series, (c) Estimated epidemic curves from reported (solid line) and TN (dotted line) epidemic incidence using 
medRxiv preprint doi: https://doi.org/10.1101/2020.03.19.20038729; this version posted March 20, 2020. The copyright holder for this preprint (which was not certified by peer review) is the author/funder, who has granted medRxiv a license to display the preprint in perpetuity. It is made available under a CC-BY-NC-ND 4.0 International license .

only the first 7 days of data after the first reported case to approximate realtime parameter estimation and resulting prediction.

560 

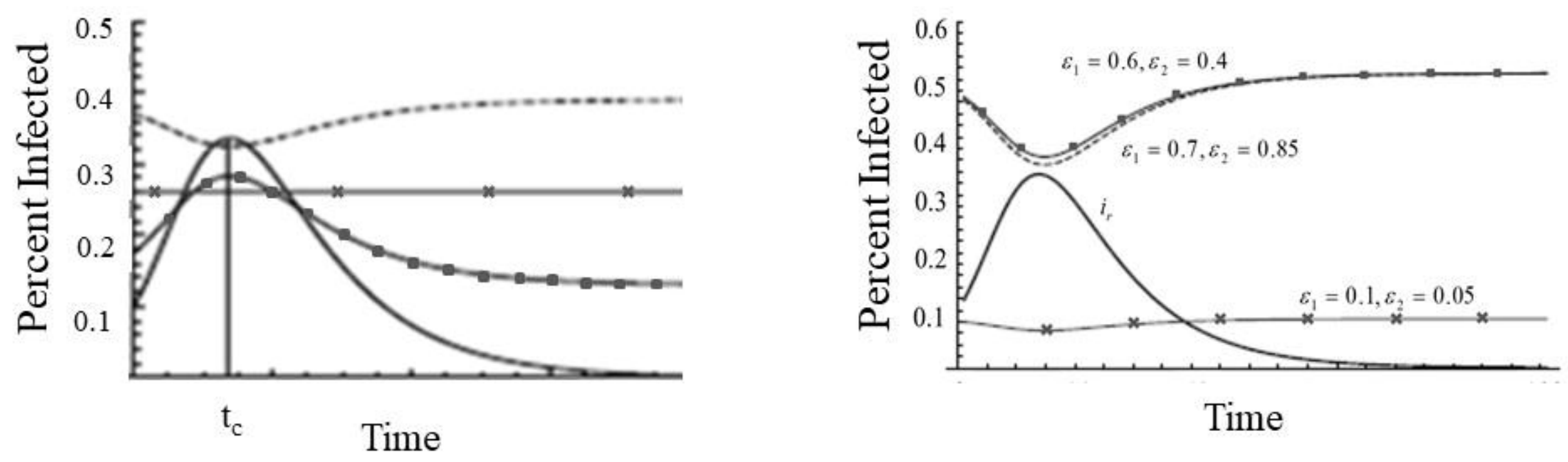

Figure 1 


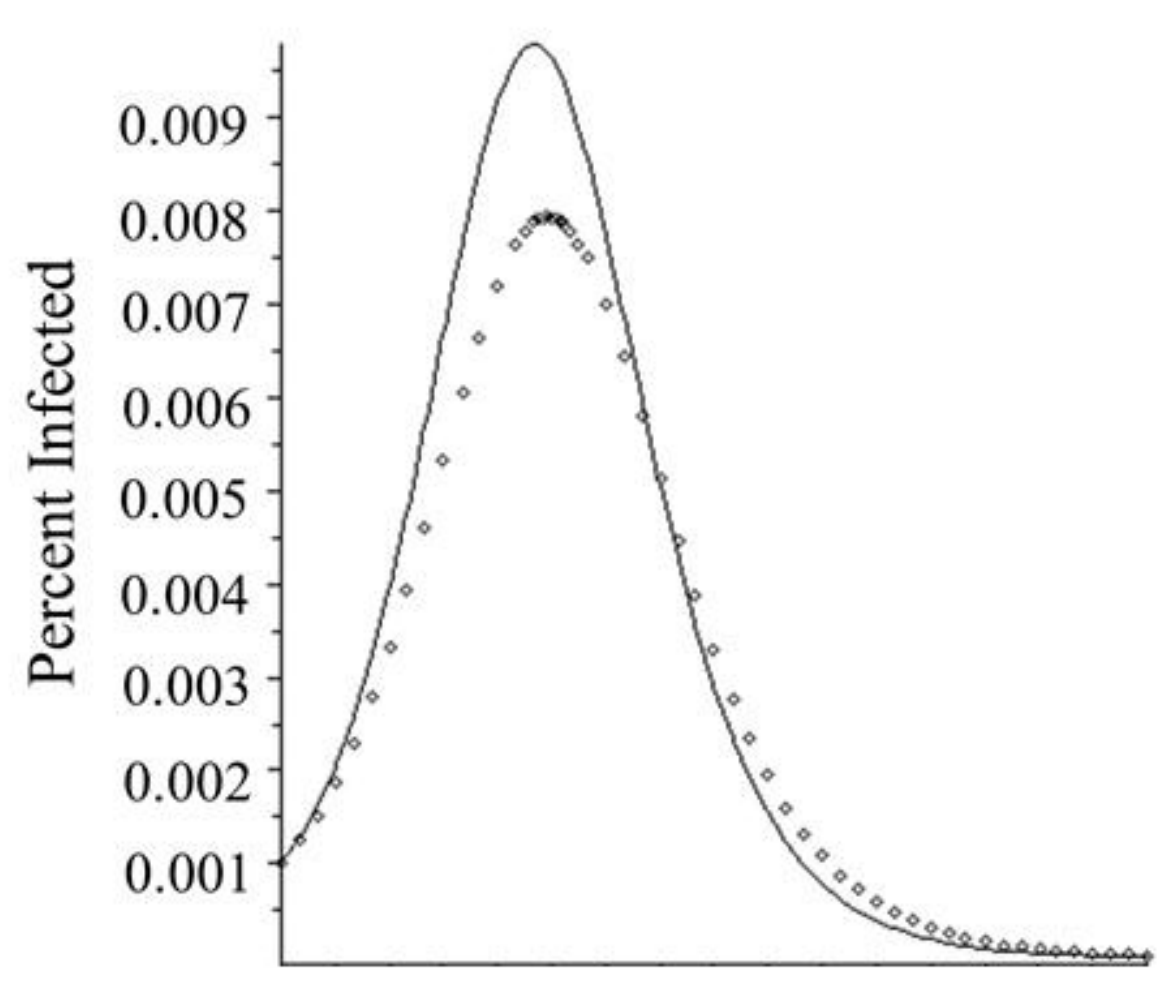

Time

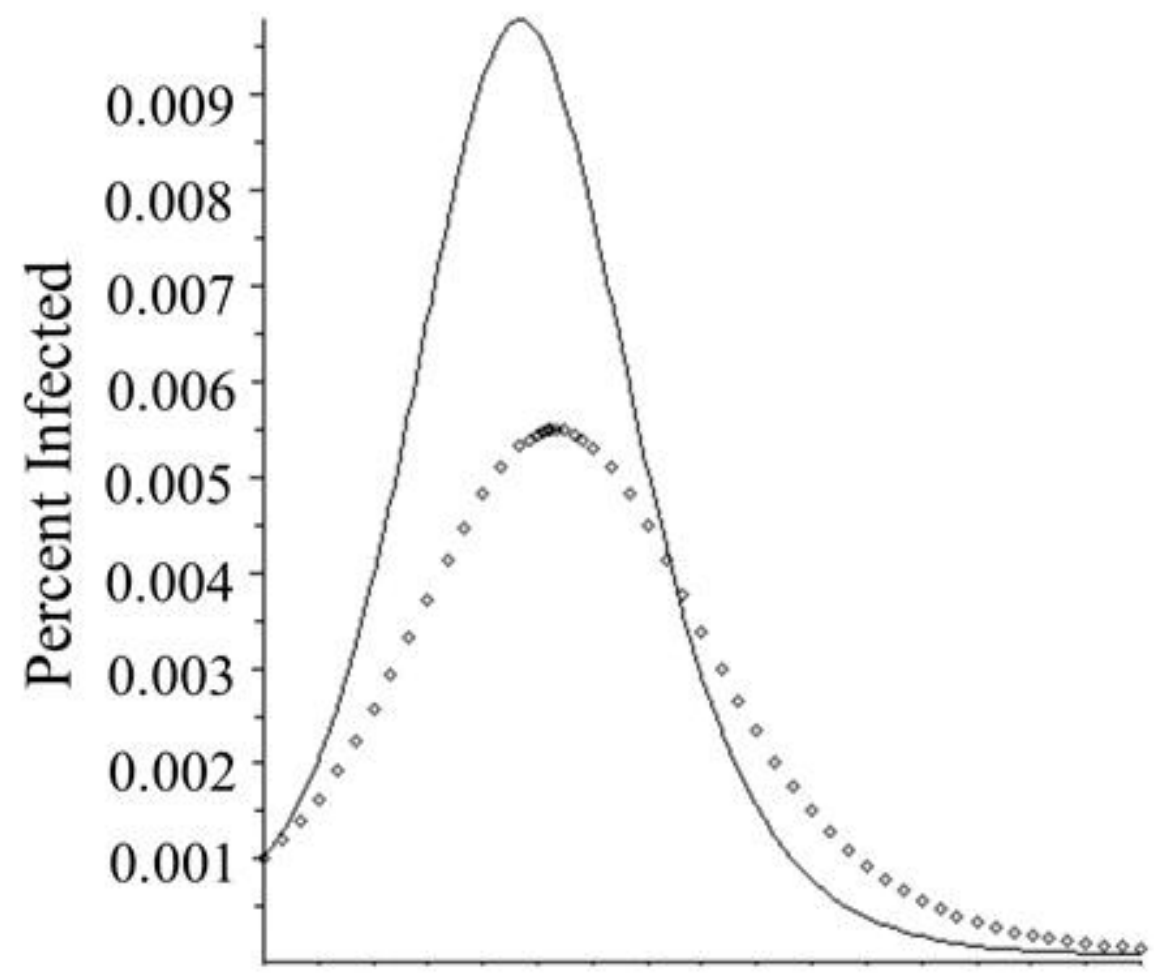

Time

Figure 2 

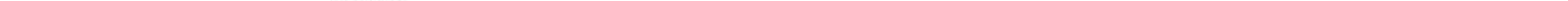

Figure 3 
(a)

(b)

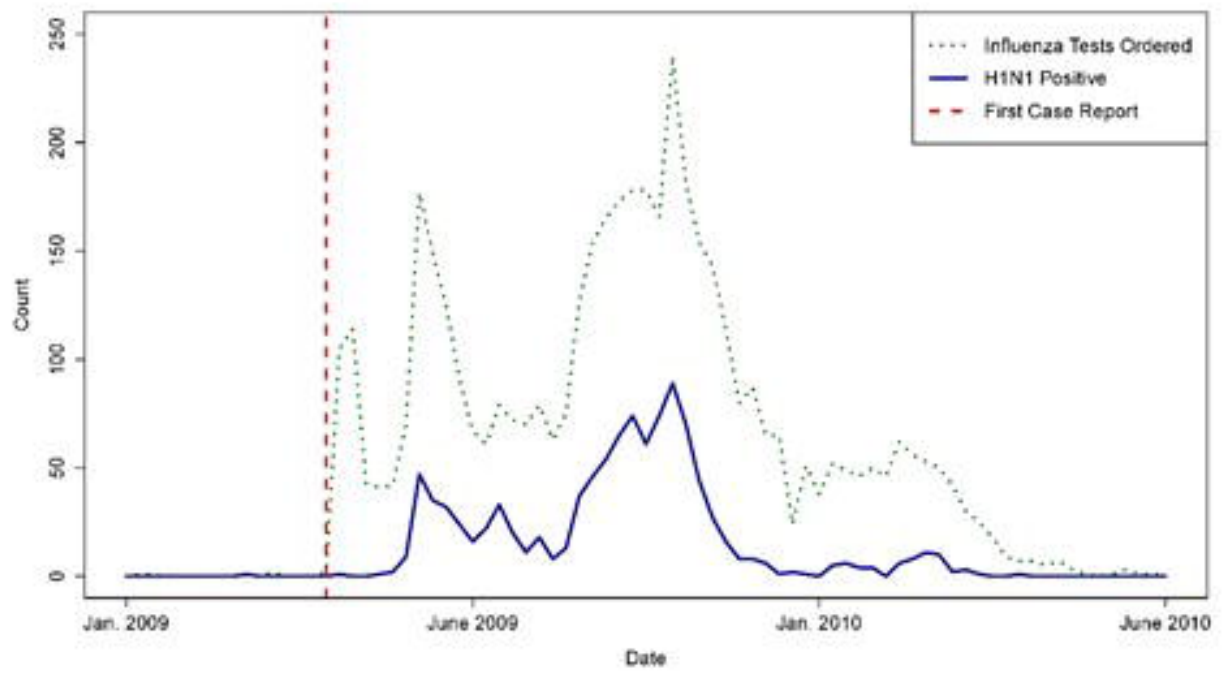

(c)

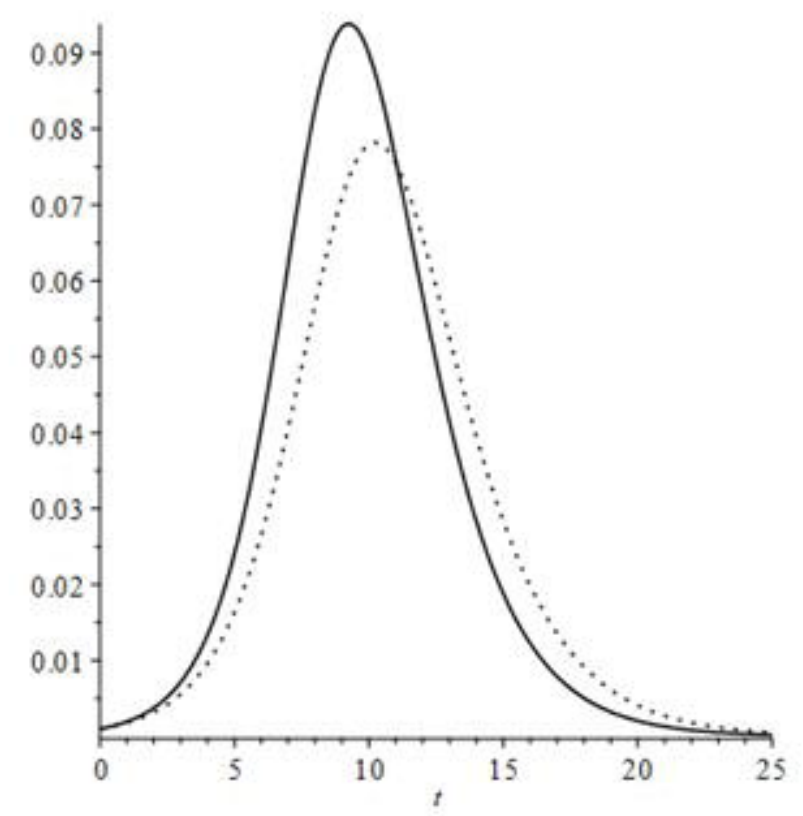

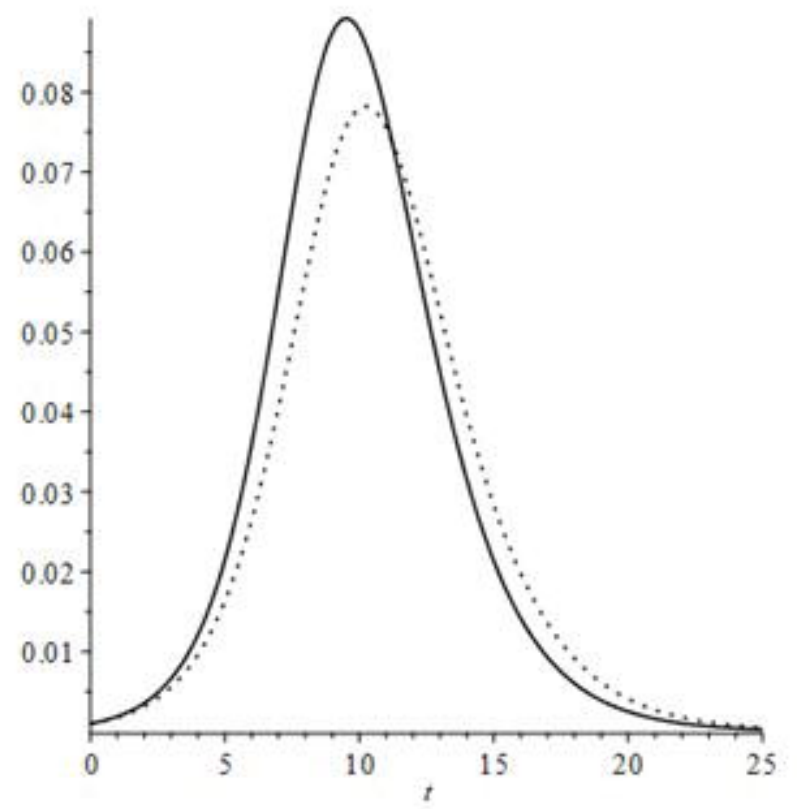

Figure 4 